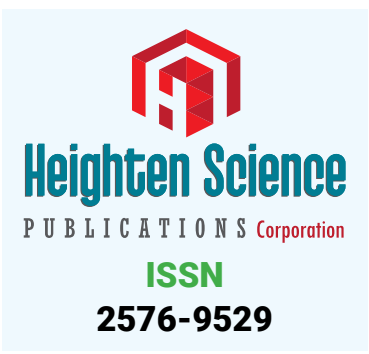

*Address for Correspondence: Dr. Sumbal Nasir Mahmood, Professor and Head of Nephrology Department at Ziauddin Hospital, Karachi,

Pakistan. Email: sumbaloo@yahoo.com

Submitted: 19 February 2018

Approved: 07 March 2018

Published: 08 March 2018

Copyright: @ 2018 Mahmood SN. et al. This is an open access article distributed under the Creative Commons Attribution License, which permits unrestricted use, distribution, and reproduction in any medium, provided the original work is properly cited.

Keywords: Hyponatremia; Osmotic

demyelination syndrome; Plasma exchange
Case Report

\section{Complete recovery of chronic Osmotic Demyelination Syndrome with plasma exchange}

\author{
Sumbal Nasir Mahmood ${ }^{1 *}$, Kunwer Naveed Mukhtar², Osama \\ Kunwer Naveed ${ }^{3}$ and Ahmed Kunwer Naveed ${ }^{4}$ \\ ${ }^{1}$ Professor and Head of Nephrology Department at Ziauddin Hospital, Karachi, Pakistan \\ 2Professor and Head of Nephrology at Liaquat National Hospital, Pakistan \\ ${ }^{3}$ Medical Student at Dow University of Health Sciences, Karachi, Pakistan \\ ${ }^{4}$ Student at Dow University of Health Sciences, Karachi, Pakistan
}

\section{Abstract}

A 50-years old female presented with dysarthria, inability to swallow and quadriparesis for three weeks She had rapid correction of her serum sodium $(\mathrm{Na})$ from $99 \mathrm{meq} / \mathrm{l}$ to $138 \mathrm{meq} / \mathrm{l}$ within 24 hours 1 week prior to development of these symptoms. She was diagnosed as a case of Osmotic demyelination syndrome (ODS) formerly known as central pontine myelinolysis (CPM) which was confirmed by MRI. She underwent Plasma Exchange (PE) on the 20th day since her symptoms started and underwent 7 cycles of PE with complete neurological recovery. Pt was discharged with ability to ambulate independently and complete recovery of speech and swallowing. Hence, we report that PE is beneficial in chronic ODS.

\section{Introduction}

ODS is a neurological disorder that occurs due to rapid correction of chronic hyponatremia and results in damage to blood brain barrier by osmotic fluctuations. It has also been reported to occur in relation to hyperosmolality, liver transplantation, hemodialysis and alcohol abuse but its strongestassociation is with rapid overcorrection of hyponatremia. Clinically it is manifested as dysarthria, dysphagia, quadriparesis, seizures and coma. Once established, the syndrome is usually considered irreversible, however in recent years multiple case reports have been published that have shown that implementing strategies like relowering the Na, use of desmopressin (DDAVP), immunoglobulins and PE can reverse the symptoms of ODS. We report this case in which PE corrected the symptoms of chronic ODS with complete recovery weeks after its occurrence.

\section{Case Report}

A 50-years old female with past medical history significant for Hypertension for 10 years, chronic kidney disease secondary to chronic pyelonephritis with baseline creatinine (Cr) of $2.6 \mathrm{mg} / \mathrm{dl}$ estimated GFR of $28 \mathrm{ml} / \mathrm{min}$ was admitted at an outside facility 3 weeks prior to presenting at our hospital with complaints of persistent severe vomiting and fever of 3 days duration. She was diagnosed to be suffering from E.coli urosepsis and hypovolemic hyponatremia with initial $\mathrm{Na}$ level of $99 \mathrm{meq} / \mathrm{l}$. On initial presentation she was drowsy but arousable and was able to follow simple commands. Her vitals showed pulse of $120 / \mathrm{min}$ and BP of $80 / 40$. She was resuscitated with Intravenous (IV) $0.9 \%$ normal saline and give IV broad spectrum antibiotics. She received 5 liters of $0.9 \%$ normal saline in 24 hours. Initially she received two liters $0.9 \%$ normal saline as bolus over 4 hours for hemodynamic stability and then the 
intravenous saline was continued at a rate of $150 \mathrm{ml} / \mathrm{hr}$ for next 20 hours. Her Na was corrected to $138 \mathrm{meq} /$ lit within 24 hours of her admission. 3 days later she was noted to be more drowsy and mute and was transferred to another facility. Patient continued to deteriorate with development of dysphagia and quadriparesis. Nasogastric tube was inserted for feeding purpose. Initial lab studies at the $2^{\text {nd }}$ hospital showed $\mathrm{Na}$ of $130 \mathrm{meq} / \mathrm{l}$ and $\mathrm{Cr}$ of $3.2 \mathrm{mg} / \mathrm{dl}$. After 15 days of admission and no improvement in her neurological status patient was transferred to our hospital.

On arrival at our hospital, patient was lethargic, drowsy but arousable, slow to respond and was able to recognize her name by blinking of eyes. She was dysarthric with noncomprehendible speech and generalized body stiffness. NG tube was in place. Vital signs were normal. Tone was increased in all 4 limbs and power was $2 / 5$ in all extremities. Babinski was negative and reflexes were mute. Rest of the systemic exam was unremarkable. Initial lab data showed normal TLC and platelets. Hb was $8.7 \mathrm{mg} /$ $\mathrm{dl}$, Na 143meq/l urea $83 \mathrm{mg} / \mathrm{d} /$ and $\mathrm{Cr}$ of $3.5 \mathrm{mg} / \mathrm{dl}$. Other electrolytes and calcium, phosphorus levels were normal. Ultrasound kidneys showed slightly decreased renal size with irregular contour and mild cortical atrophy bilaterally. Urine DR showed protein 2+ and 15-20 leukocytes. Based on her history and previous record review a diagnosis of ODS was made. MRI brain was done that showed findings consistent with ODS (Figure 1). As patient had full manifestations of ODS and with literature reports of PE being beneficial as well as our prior experience we decided to treat this patient with PE. She underwent $1^{\text {st }}$ cycle of PE 10 hours after admission and her dysarthria improved. The next day second cycle of PE was performed and her GCS improved to 15/15. After the third session she was able to sit by herself and able to communicate. Her dysphagia also improved and NG tube was removed. Her power in all her limbs was now $5 / 5$, she was able to stand with support and she was discharged home with advice to continue PE as outpatient. Another cycle was done 2 days after discharge after which she was able to take a few steps and after 2 more cycles she was ambulating without support. PE was discontinued. She presented 1 week later with dysarthria and lower limb weakness which responded to another cycle of PE. Patient was followed 2 weeks later as outpatient and had no complaints.

\section{Discussion}

The patient when presented initially to the first hospital had severe hypovolemic hyponatremia as well as low solute intake. Rapid correction occurred due to volume and solute repletion given for hemodynamic instability, however it was not timely recognized and resulted in the development of ODS. If the $\mathrm{Na}$ would have been relowered with use of dextrose water (D5W) and desmopressin (DDAVP) as recommended in literature [1,2] the patient might have not suffered so severely. Patient developed all the severe symptoms reported with the syndrome including

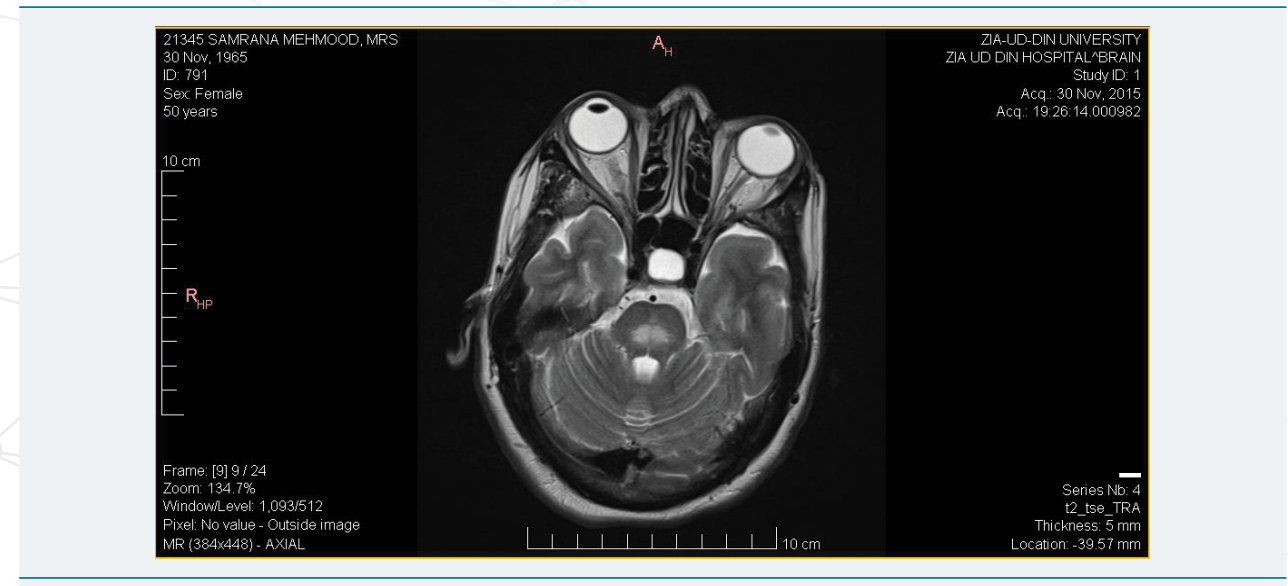

Figure 1: MRI of brain showing high intensity symmetrical signals in pons in T2W image suggestive of ODS. 
dysarthria, dysphagia and quadriparesis. Treatment modalities that have been tried in such cases include administration of corticosteroids, thyrotropin releasing hormone $[3,4]$, immunoglobulins [5] and PE [6] but no therapy has been proven to be effective. The patient presented to us almost 3 weeks after her symptoms had developed and was considered to have ODS. At this stage we did not expected that relowering $\mathrm{Na}$ or DDAVP will be useful so we decided to treat her with PE as it has been shown to be effective in treating demyelinating neuropathy [7]. Patient had remarkable response to the treatment with signs of improvement immediately after the $1^{\text {st }}$ cycle and continued improvement after each cycle. She did relapse when the PE was discontinued but recovered again with reinstitution of therapy.

A study published by Louis G [8], on long term outcome of ODS had showed dismal results with $31 \%$ patients dying and another $31 \%$ requiring lifelong supportive therapy in established ODS. This was probably when ODS was considered irreversible. Our case gives hope that PE is beneficial even in chronic established cases of ODS. A similar case report has been published by Kumon S [9], which showed complete recovery of ODs when PE was initiated on the $39^{\text {th }}$ day of hospitalization.

\section{Conclusion}

We conclude that PE is beneficial in chronic ODS and should be tried as it may prevent significant morbidity and mortality in these patients.

\section{References}

1. Gankam Kengne F, Soupart A, Pochet R, Brion JP, Decaux G. Reinduction of hyponatremia after rapid overcorrection of hyponatremia reduces mortality in rats. Kidney Int. 2009; 76: 614-621. Ref.: https://goo.gl/PKiHd9

2. Yamada H, Takano K, Ayuzawa N, Seki G, Fujita T. Relowering of serum Na for osmotic demyelinating syndrome. Case Rep Neurol Med. 2012. Ref.: https://goo.gl/z8LR7n

3. Chang KY, Lee IH, Kim GJ, Cho K, Park HS, et al. Plasma exchange successfully treats central pontine myelinolysis after acute hypernatremia from intravenous sodium bicarbonate therapy. BMC Nephrol. 2014; 15: 56. Ref.: https://goo.gl/ukH27g

4. King JD, Rosner MH. Osmotic Demyelination syndrome. Am J Med Sci. 2010; 339: 561-567. Ref.: https://goo.gl/aqpUEZ

5. Murthy SB, Izadyar S, Dhamne M, Kass JS, Goldsmith CE. Osmotic demyelination syndrome: variable clinical and radiologic response to intravenous immunoglobulin therapy. Neurol Sci. 2013; 4: 581584. Ref.: https://goo.gl/TepmcX

6. Sardar GK, Eilbert WP. Severe hyponatremia associated with thiazide diuretic use. J Emerg Med. 2015; 48: 305-309. Ref.: https://goo.gl/ZLLjTA

7. Koller $\mathrm{H}$, Kieseier $\mathrm{BC}$, Jander $\mathrm{S}$, Hartung HP. Chronic inflammatory demyelinating neuropathy. $\mathrm{N}$ Engl J Med. 2005; 352: 1343-1356. Ref.: https://goo.gl/MN8xN8

8. Louis G, Megarbane B, Lavoue S, Lassalle V, Argaud L, et al. Long term outcome of patients hospitalized in intensive care units with central or extrapontine myelinolysis. Crit Care Med. 2012 40: 970-972. Ref.: https://goo.gl/5JRo4Z

9. Kumon S, Usui R, Kuzuhara S, Nitta K, Koike M. The improvement of the outcome of osmotic demyelination syndrome by Plasma exchange. Intern Med. 2017; 56: 733-736. Ref.: https://goo.gl/1zgNYY 